\title{
Gérard Du Vivier (de Vivre), Grammaire françoise (1566) suivie de Briefve insitution de la langue françoise expliquée en aleman (1586)
}

\section{Michele Mastroianni}

\section{(2) OpenEdition \\ Journals}

Edizione digitale

URL: http://journals.openedition.org/studifrancesi/9472

DOI: 10.4000/studifrancesi.9472

ISSN: 2421-5856

\section{Editore}

Rosenberg \& Sellier

\section{Edizione cartacea}

Data di pubblicazione: 1 décembre 2007

Paginazione: 640

ISSN: 0039-2944

\section{Notizia bibliografica digitale}

Michele Mastroianni, «Gérard Du Vivier (de Vivre), Grammaire françoise (1566) suivie de Briefve insitution de la langue françoise expliquée en aleman (1586)», Studi Francesi [Online], 153 (LI | III) | 2007, online dal 30 novembre 2015, consultato il 08 janvier 2021. URL: http://journals.openedition.org/studifrancesi/ 9472 ; DOI: https://doi.org/10.4000/studifrancesi.9472

Questo documento è stato generato automaticamente il 8 janvier 2021.

\section{cc)}

Studi Francesi è distribuita con Licenza Creative Commons Attribuzione - Non commerciale - Non opere derivate 4.0 Internazionale. 


\title{
Gérard Du Vivier (de Vivre), Grammaire françoise (1566) suivie de Briefve insitution de la langue françoise expliquée en aleman (1586)
}

\author{
Michele Mastroianni
}

\section{NOTIZIA}

GÉRARD DU VIVIER (DE VIVRE), Grammaire françoise (1566) suivie de Briefve insitution de la langue françoise expliquée en aleman (1586), traduction et notes de Brigitte HÉBERT, Paris, Champion, 2006 («Textes de la Renaissance», 103), pp. 185.

Colonia nel Cinquecento, capitale del territorio renano, è centro privilegiato per gli scambi fra i paesi germanici e la Francia ed è un carrefour importante, ove si incontrano Fiamminghi e Valloni di cultura bilingue. Vi si aprono scuole per insegnare il francese, in particolare ai figli dei mercanti che usano questa lingua nei loro rapporti commerciali. Uno degli insegnanti è Gérard Du Vivier (Duvivier, de Vivre, de Vivres, Du Vivre, van den Vivre, vanden Vivre; il nome fiammingo originale sarebbe Geeraert vanden Vijvere o Vivere), nato a Gand nella prima metà del Cinquecento e la cui lingua materna era il fiammingo, il quale nel 1563 si stabilisce a Colonia, ove un anno più tardi ottiene l'autorizzazione di aprire una scuola per insegnare il francese. Nel $1566 \mathrm{Du}$ Vivier pubblica una grammatica per l'uso didattico e pratico dei parlanti tedesco, che sembra essere la prima opera sistematica comparsa in volgare in Germania. Nella consuetudine dell'epoca si ispira alla grammatica latina, i cui capitoli trattano le parti del discorso, e nello stesso tempo vuole facilitare l'apprendimento del francese ai giovani che ignorano il latino. Due anni dopo, Du Vivier fa seguire la grammatica da una Briefve institution de la langue françoise commentata e spiegata in tedesco. Anche la Grammaire ha delle brevi formule di spiegazione in tedesco e in tedesco sono tradotti gli 
esempi. La presente edizione traduce in francese moderno, per entrambi i manuali, le parti esplicative in lingua tedesca. In nessun luogo l'autore fa riferimento alla teoria o a modelli teorici: ma l'interesse di questa edizione è proprio di fornire un'interessante testimonianza di due manualetti pratici, basati su un metodo del tutto pragmatico, in quanto la pedagogia di Du Vivier è fondata sulla ripetizione, sulla memorizzazione e sulla traduzione, piuttosto che sulla comprensione e sulla spiegazione dei fatti linguistici. 